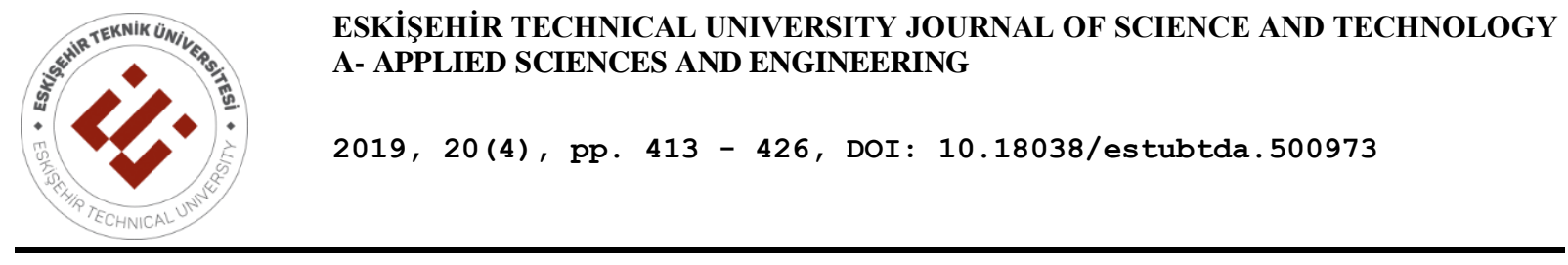

\title{
EVALUATION OF RIGID BODY SLIDING ANALYSIS FOR MODULAR STEEL STRUCTURES SUBJECTED TO BLAST LOADING
}

\author{
Bülent ERKMEN ${ }^{1, *}$, Bilal BALCI ${ }^{2}$ \\ ${ }^{1}$ Civil Engineering Deparment, Engineering Faculty, Özyeğin University, İstanbul, Turkey \\ ${ }^{2}$ Civil Engineering Deparment, Engineering Faculty, Özye ğin University, İstanbul, Turkey
}

\begin{abstract}
Blast resistant modular steel (BRMS) buildings are prefabricated cost-effective and explosion-proof structures used to shelter personal near hazardous-material handling or storage facilities, in facilities handling high-pressure processes, and within designed blast zones in mining, petrochemical, and military industries. Typically, BRMS buildings are designed to be fixed (anchored) to their foundation. However, this design approach can result in very large anchorage and foundation reactions, which result in very large and high-cost foundations. Therefore, an alternative foundation approach which minimize foundation reactions and known as unanchored or free-to-slide foundation has recently attracted much attention for BRMS buildings. In this study, dynamic behavior of a typical BRMS building under blast loading with unanchored foundation was determined using 3D nonlinear dynamic finite element and a simplified numerical analysis method. The developed numerical analysis method is based on nonlinear numerical integration scheme, and it was verified using the finite element results. Applicability of the proposed numerical analysis method was evaluated using finite element results for a typical unachored BRMS building subjected to blast loads. Several values of coefficient of friction between the foundation and BRMS building were considered. The computed building sliding, horizontal velocity, acceleration, and horizontal foundation reaction histories were used to evaluate applicability of the proposed numerical method. The overall results show that the proposed simple numerical analysis method based on rigid-body dynamics is suitable to predict building sliding and sliding velocity, but unconservative in terms of foundation vertical reaction and horizontal acceleration.
\end{abstract}

Keywords: Blast, Numerical integration, Modular steel building, Sliding foundation

\section{INTRODUCTION}

Accidental blast incidents and growing terror threats have significant consequences including structural collapse, personal casualties, and financial losses in military, mining, and petrochemical industries $[1,2,3,4]$. Therefore, blast performance of structures is becoming an important design consideration for not only military structures but also for structures located at or near potential blast zones. However, blast resistant structures can be extremely costly due to high magnitude of blast loads and their dynamic effects [2]. To minimize cost, prefabricated blast resistant modular steel (BRMS) structures have recently become very common as economic solutions especially in petrochemical industry as control rooms, office buildings, and living quarters [1].

An important design challenge for blast resistant buildings is the extremely high foundation dynamic reactions and consequently the requirement for large foundations to anchor the structures [2]. Another problem with especially BRMS buildings is that they are typically placed at already existing sites, where digging for such big foundations is not practical and sometimes not even possible. Therefore, to minimize foundation requirements and foundation reactions, the BRMS structures may be left unconnected to their foundation for blast loads but connected to the foundation only for environmental loads such as seismic and wind loads. This new design approach, which is called "free-to-slide" or "unanchored" foundation is gaining an increased acceptance in the petrochemical industry.

*Corresponding Author: bulent.erkmen@ozyegin.edu.tr

Received: 22.12.2018 Published: 30.12 .2019 
Blast design and analysis of BRMS structures is typically done by performing dynamic analysis using 3D nonlinear finite element (FE) models [1,2,3,5]. However, such nonlinear dynamic analyses can be very costly in terms of computational requirements when the structure is also sliding on its foundation. In other words, performing such dynamic sliding analysis with very small-time steps using commercial finite element packages is computationally costly, requires advanced finite element knowledge including dynamic interaction, and contact separation between model building and its foundation [3]. Therefore, dynamic analysis approaches based on rigid-body motion of the structure are commonly used in the industry to predict building velocity, acceleration, sliding, and its interaction with the foundation.

The paper discusses development of a simple but computationally cheap and effective numerical integration method based on rigid body dynamics to predict overall blast performance of unanchored (free-to-slide) structures. The developed numerical method to predict foundation reactions and sliding acceleration, velocity, and sliding distance of BRMS buildings is based on the assumption that the structure behaves as a rigid body. In other words, deformation of the structure and its structural members is neglected. However, typically these structures are designed to go under significant structural damage (i.e., plastic deformation) to minimize the associated construction costs [1,2,3]. Therefore, a part of structure's kinetic energy is dissipated by the structural elements through cyclic plastic deformations. Therefore, theoretically it is assumed that the rigid body approximation is a conservative approach to predict building overall sliding motion under blast loads. However, to the best of authors' knowledge, this is the first study documenting the magnitude of error associated with the rigid body approximation. Verification and evaluation of the numerical method are also performed by comparing the numerical integration analysis results with those from 3D finite element analyses for a prototype BRMS building.

\section{PROTOTYPE BRMS BUILDING}

The prototype BRMS building studied is a typical two-module building. Each module has a length of $12 \mathrm{~m}$, width of $3 \mathrm{~m}$, and height of $3.5 \mathrm{~m}$ as shown in Figure 1 and Figure 2. The building frame members were selected to be seismically compact hollow structural sections (HSS) per AICS [6,7] so that their full bending plastic capacity can be reached before occurrence of any local instability. The only non HSS sections are the roof and floor joists, which are seismically compact W4x13 I-beam sections. Flat $5 \mathrm{~mm}$ thick steel plates were used for the roof and floor covering while $5 \mathrm{~mm}$ thick crimp panels (trapezoidal cross-section) were used for the walls. The two modules are identical, and they were connected rigidly at the column line B by welding the two columns to each other on the filed using flare grove weld along the columns. A summary of structural members is given Table 1. A detailed description of the structure is given by Erkmen [3].

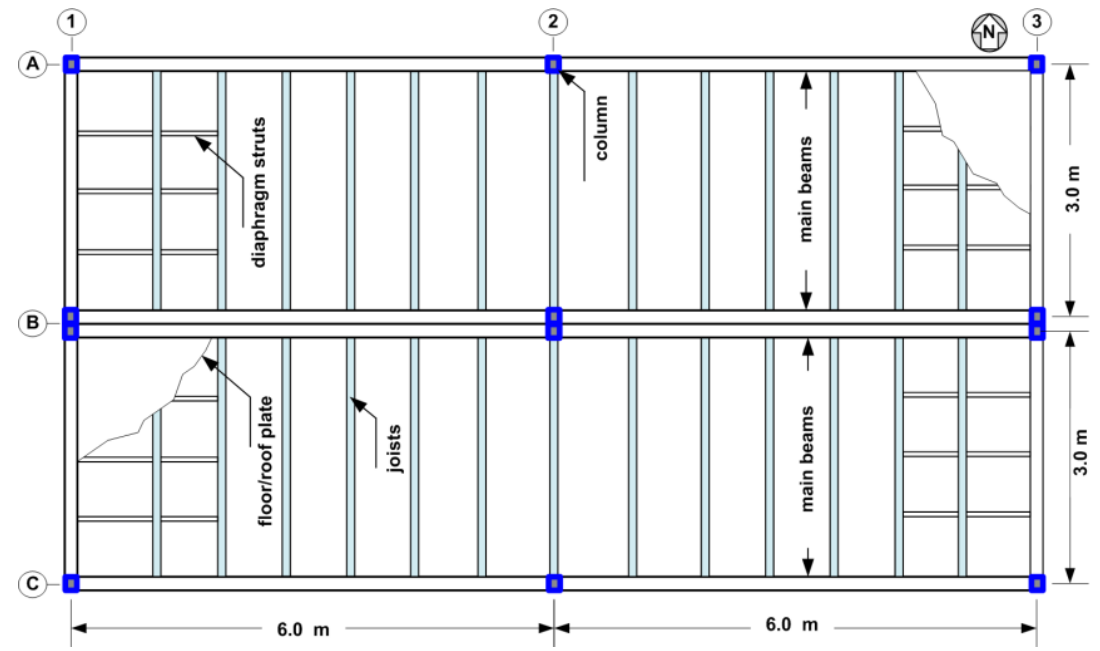

Figure 1. Prototype building floor and roof plan view 
Erkmen and Balcı / Eskişehir Tech. Univ. J. of Sci. and Technology A-Appl. Sci. and Eng. 20 (4) - 2019

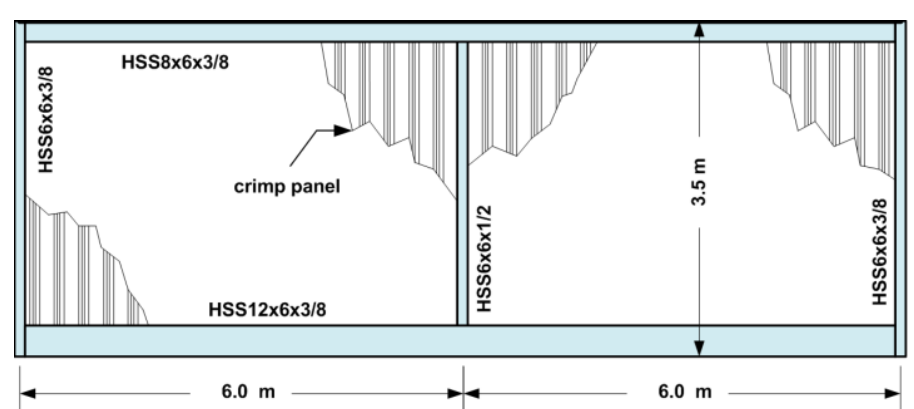

(a)

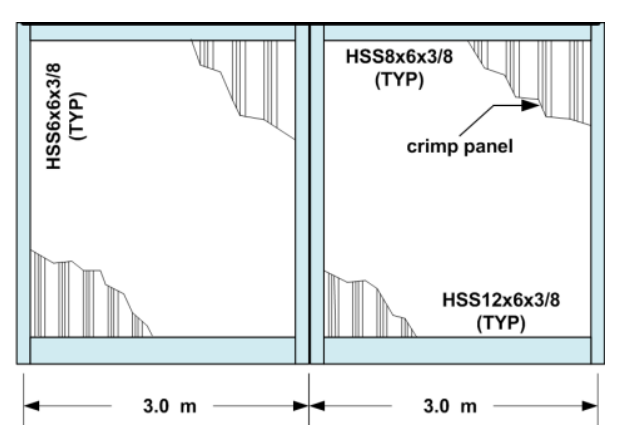

(b)

Figure 2. Prototype building elevation view (a) at column line-A and (b) at column line-1

Table 1. Summary of structural members for prototype building

\begin{tabular}{lll}
\hline \multicolumn{1}{c}{ Frame Members } & \multicolumn{1}{c}{ Steel Grade } & \multicolumn{1}{c}{ Section } \\
\hline Corner columns (total of 8) & A500 Gr. B & HSS6x6x3/8 \\
Other columns (total of 4) & A500 Gr. B & HSS6x6x1/2 \\
Top perimeter longitudinal main beams (total of 2) & A500 Gr. B & HSS8x6x3/8 \\
Top intermediate longitudinal main beams (total of 2) & A500 Gr. B & HSS8x6x1/2 \\
Top perimeter transverse main beams (total of 4) & A500 Gr. B & HSS8x6x3/8 \\
Top intermediate transverse main beams (total of 2) & A500 Gr. B & HSS6x6x3/8 \\
Bottom longitudinal main beams (total of 4) & A500 Gr. B & HSS12x6x3/8 \\
Bottom transverse main beams (total of 4) & A500 Gr. B & HSS12x6x3/8 \\
Roof and floor joists & A992 Gr. 50 & W4x13 \\
Roof and floor diaphragm struts at module end & A500 Gr. B & HSS3x2x3/16 \\
\hline
\end{tabular}

\subsection{Building Foundation}

The prototype building was assumed to be free-to-slide (unachored) on a rigid foundation. For horizontal motion of the building, static and dynamic friction coefficients for interaction between the building and its foundation were assumed to be equal. Three values of friction coefficient $0.2,0.5$ and 0.8 were considered for building blast analyses. While value of 0.5 for friction coefficient between concrete and steel is considered to be reasonable, values of 0.2 and 0.8 were considered only to evaluate the proposed simplified numerical analysis method for small and large sliding distances. For the building and its foundation, total nine contact points were assumed. The size of these contact points, which does not affect the results presented, was assumed to be as large as cross section of its columns (i.e., $15 \mathrm{~cm}$ x15 $\mathrm{cm})$. The contact points were assumed to be located under the columns at Column Lines A, B, and C.

\subsection{Blast Loads}

The blast source was assumed to be located on the north side of the building with blast wave directly striking its broad side. Blast loads are usually described in terms of free field overpressure known as incident or side-on overpressure, which is the blast pressure before it is reflected from any surface. Typical blast peak side-on overpressure due to explosions in petrochemical industry is between $10-100 \mathrm{kPa}$ with a duration of 20-200 ms [2]. The blast pressure was assumed to have a triangular shape with a maximum peak side-on pressure of $80 \mathrm{kPa}$ and a duration of $140 \mathrm{~ms}$. The selected blast load corresponds to high damage level for the prototype BRMS building. Different building damage levels are described for structures in petrochemical industry for blast loads, and details of these damage levels are given in several references $[2,4,8,9]$. Blast loads corresponding to building high damage level were selected to maximize 
blast damage on the building structural members since larger damage level indicates higher plastic deformation of structural members and larger deviation from rigid body approximation.

The interaction of blast waves with building walls and roof is quite complex. Therefore, a simplified method proposed by ASCE [2] was used to determine blast pressure curves, which are given in Figure 3, for each wall and roof as well as the free-field overpressure, which is the pressure of blast wave before it hits any surface.

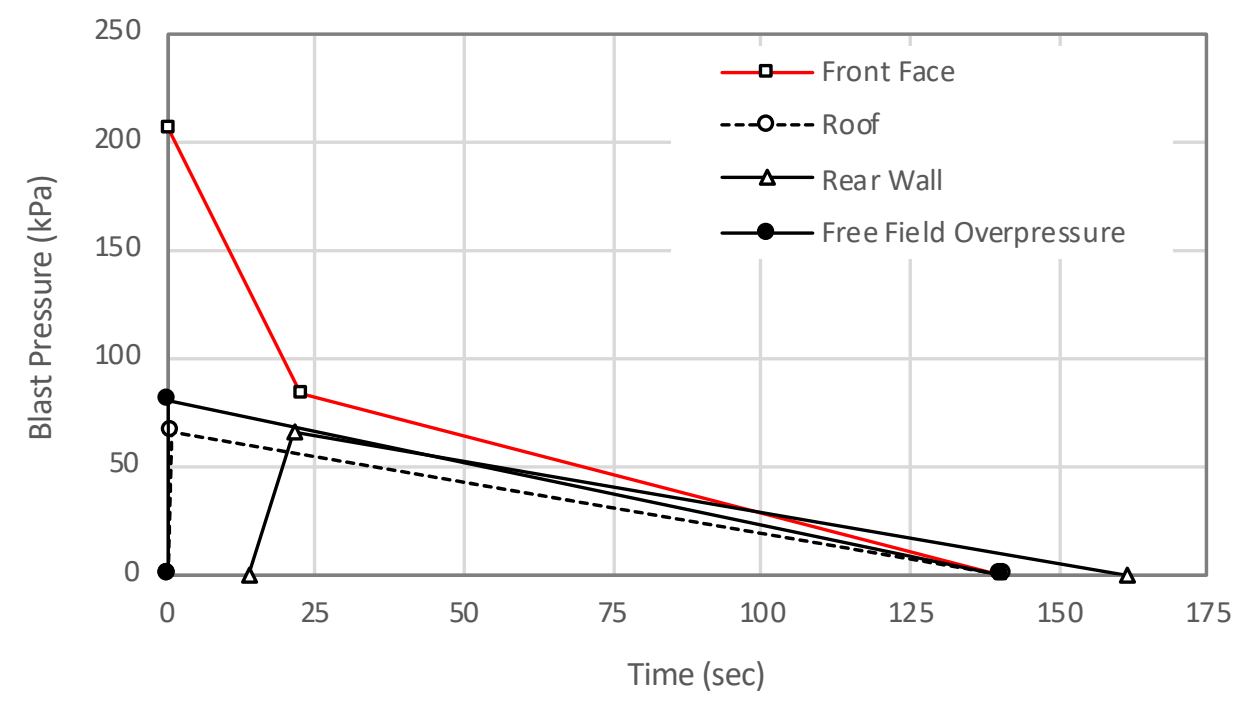

Figure 3. Blast loads on individual walls and free field overpressure

\section{NUMERICAL INTEGRATION ANALYSIS METHOD (RIGID BODY APPROACH)}

A nonlinear numerical integration method was developed to predict velocity, acceleration, displacement, and building foundation reactions based on the assumption that the structure deformation does not affect the overall motion of the building. In other words, the building is assumed to be rigid under applied blast loads. This assumption is typically considered to be conservative since the energy dissipated through the member deformation (plasticity) is conservatively neglected $[2,10]$.

Figure 4 shows free-body diagram of a BRMS building under blast loads and dead loads. The blast loads considered are front wall, roof, and rear wall blast-pressure versus time curves. The blast loads on other two walls are not considered since the loads on those walls do not affect the motion of the structure in blast direction (i.e., X-direction). In addition to blast loads, structure self-weight and dynamic interaction between the structure and its foundations (i.e., normal load and friction load) were also considered. 


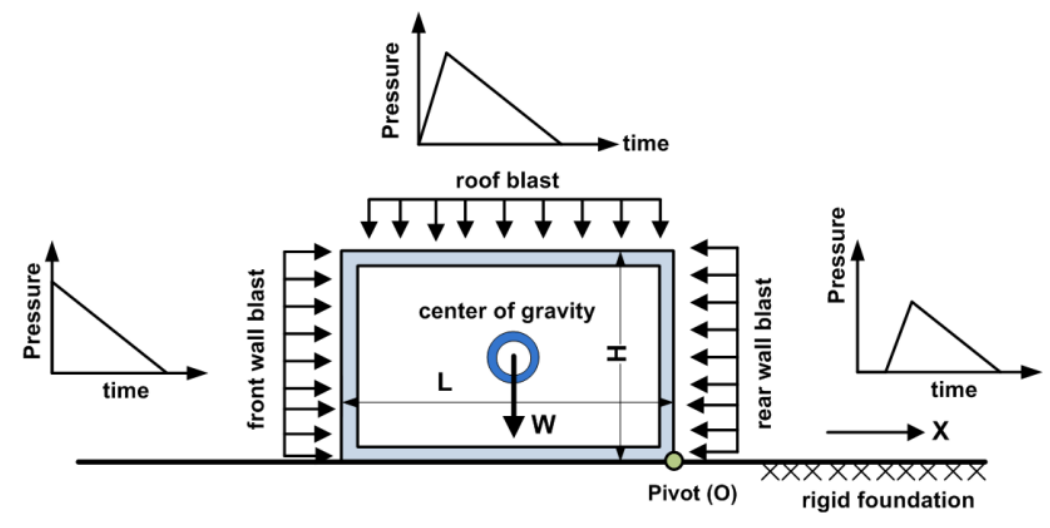

Figure 4. Free-body diagram of building under blast load

The system of forces on the building consist of front face $\left(P_{\text {Front }}(t)\right)$, roof $\left(P_{\text {Roof }}(t)\right)$, and rear wall $\left(P_{\text {rear }}\right.$ $(t))$ blast pressures, which vary with time, and self-weight of the building $(W)$, which is a constant vertical load. The net vertical force $F_{V}(t)$ on the building is given as;

$$
F_{V}(t)=W+P_{R o o f}(t) A_{R o o f}
$$

where $A_{R o o f}$ is the total roof surface area of the building. The net horizontal force $F_{H}(t)$ is calculated as the sum of the front and rear wall loads plus a friction force equivalent to the product of net vertical force and friction coefficient $(\mu)$. The net horizontal force is given as;

$$
F_{H}(t)=P_{\text {Front }}(t) A_{\text {Front }}+P_{\text {Rear }}(t) A_{\text {Rear }}+\mu F_{V}(t)
$$

Typically, the front wall and rear wall blast surface areas $\left(A_{\text {Front }}\right.$ and $\left.A_{\text {Rear }}\right)$ are equal, and front and rear wall blast pressures act in opposite directions while the friction force $\left(\mu F_{V}(t)\right)$ always opposes the direction of the motion. The instantaneous horizontal acceleration of the building is given as;

$$
\ddot{x}(t)=F_{H}(t) /(W / g)
$$

where $g$ is the gravitational constant. The instantaneous horizontal velocity $(\dot{x}(t))$ and displacement $(x(t))$ are calculated using central difference integration scheme as given by;

$$
\begin{aligned}
& \dot{x}(t)=\dot{x}(t-\Delta t)+\ddot{x}(t) \Delta t \\
& x(t)=x(t-\Delta t)+\dot{x}(t) \Delta t
\end{aligned}
$$

where $\Delta t$ is the chosen time step. Typically blast load durations are between 10 and $300 \mathrm{~ms}$, and the time step selected is much smaller. The steps described above were placed in a loop that progress through the time at a fixed time step until the desired analysis duration is reached.

Typically uplift of blast resistant buildings and overturning of whole building are not critical. However, building uplift susceptibility can be evaluated by comparing its overturning and restoring moments $[2,11]$. The overturning and restoring moments are functions of building geometry, its weight, and center 
of gravity. Both moments are independent of coefficient of friction between the building and its foundation. The overturning moment $M_{0}(t)$ is the net moment of the front and rear wall loads relative to the base of building (i.e., pivot point) about which rotation occurs in clockwise direction, and it is given as;

$$
M_{0}(t)=B H\left(P_{\text {Front }}(t)+P_{\text {Rear }}(t)\right) H / 2
$$

where $H$ and $B$ are building height and width dimensions, respectively. The front and rear wall pressures directions have opposite sign, and pressure was assumed to be uniform along the building height. On the other hand, the restoring moment is composed of moment due to building self-weight and roof blast pressure. For cases with roof pressure having negative pressure (i.e., suctions), the moment due to this negative pressure will not contribute to the restoring moment but rather to the overturning moment. The restoring moment for the building with center of gravity at its geometric center is given as follows for roof blast loads with no negative phase;

$$
M_{R}(t)=W L / 2+B L \times P_{R o o f}(t) L / 2
$$

where $L$ is the width of the building in the direction of blast load. It should be noted that if the overturning moment exceeds the restoring moment, this does not imply instability, but implies that uplift may occur for a short period of time. A gross estimation on the level of uplift can be done by assuming the net moment generates a rotational acceleration, which can be integrated in the same way as the translational motion to calculate a rotational velocity and displacement as;

$$
\begin{gathered}
\ddot{\theta}(t)=\left(M_{0}(t)-M_{R}(t)\right) / I \\
\dot{\theta}(t)=\dot{\theta}(t-\Delta t)+\ddot{\theta}(t) \Delta t \\
\theta(t)=\theta(t-\Delta t)+\dot{\theta}(t) \Delta t
\end{gathered}
$$

where $I$ is building inertia about its center of mass. Verification of this numerical integration analysis method was done by using 3D finite element blast analysis results for the prototype building.

\section{FINITE ELEMENT ANALYSIS METHOD}

The FE model of the building was developed using ABAQUS 6.14 general-purpose finite element software [12]. The three-dimensional model shown in Figure 5 consists of approximately 40,000 nodes and 38,500 beam and shell elements. All beam elements were modelled with Timoshenko B31 beam element, which is suitable for both thick and slender beams [12]. All steel plates including crimp wall panels were modelled using S4R, which is a 4-node, quadrilateral shell element with reduced integration and large-strain formulation. A nominal mesh size of $300 \mathrm{~mm}$ was used for all elements. Elasticperfectly plastic material model was assumed for all steel members. 


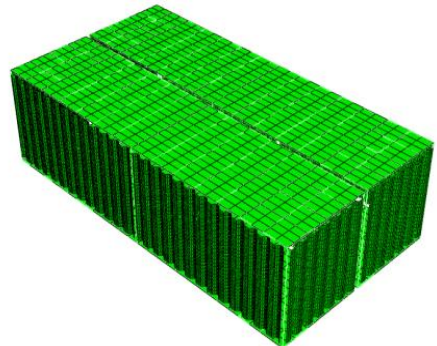

(a)

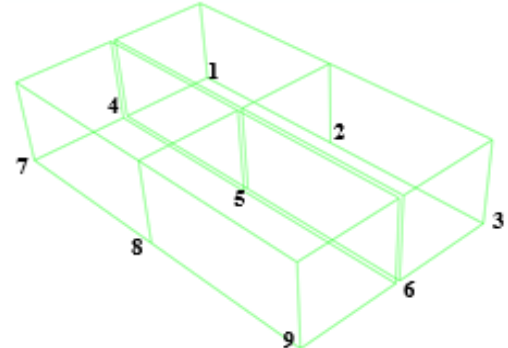

(b)

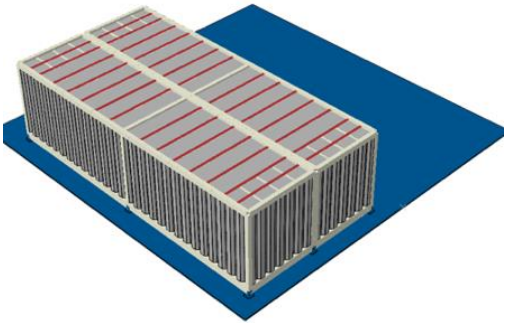

(c)

Figure 5. Building FE model (a) whole building model, (b) supports, and (c) unachored (free-to-slide) building on rigid foundation

Because the wall and roof plates are only $5 \mathrm{~mm}$ in thickness, the main mechanism that they resist out of plane blast loads is through membrane action. In addition, due to trapezoidal cross-section of the wall panels (i.e., crimped panels), the effect of nonlinear geometry (i.e., membrane action) is also important. Both effects of membrane and nonlinear geometry were included in the developed model. The building was placed on a rigid foundation and contact interaction was defined between building column baseplates (i.e., supports) and the rigid foundation. The defined contact interaction between structure and foundation allows separation of the building from its foundation (uplift). For horizontal motion of the building, static and dynamic friction coefficients for interaction between the building and its foundation were assumed to be equal, and three values of friction coefficient $0.2,0.5$ and 0.8 were considered for blast analyses of the building. The only boundary condition defined for the model was fixed boundary condition defined for the rigid foundation. All displacement and rotation degrees of freedoms for rigid foundation were fixed by coupling them to a fixed reference point located in the middle of the foundation. Building friction and vertical reaction force histories were obtained as reaction on this fixed reference point.

Blast analysis of the structure was completed in two steps. Initially, the static load (i.e., self-weight) was applied, and the blast loads on the individual walls and roof were applied at the subsequent implicit dynamic analysis step. No blast load was applied to the short side walls since the loads on these walls does not affect the sliding behavior of the structure.

\section{RESULTS AND DISCUSSION}

\subsection{Verification of Numerical Integration Analysis Method}

Verification of numerical integration analysis method was done by using the 3D building FE model developed for the prototype BRMS building. However, the steel material properties were modified such that the structure will behave as a rigid body under the applied dynamic blast loads. For this purpose, all steel materials were assumed to be linear elastic (i.e., no yielding), and the modulus of elasticity was increased by a factor of 100 .

Applied vertical loads include roof blast load and structure self-weight in the vertical direction, and horizontal loads included front and rear wall blast loads. The applied net horizontal and vertical blast load curves are given in Figure 6. Building self-weight was applied as static load and all blast pressures were applied as dynamic loads in subsequent analysis step. 


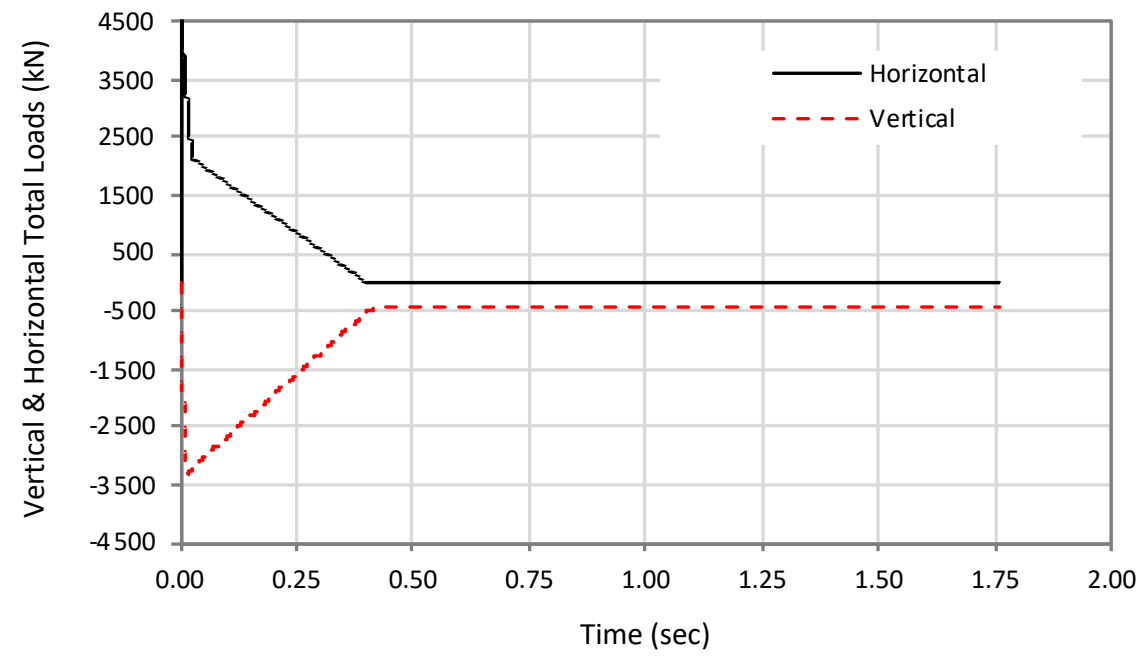

Figure 6. Total vertical and horizontal loads

Both static and dynamic friction coefficients were assumed to be equal to 0.55 . The computed and calculated histories of friction force, horizontal acceleration, horizontal velocity, and horizontal displacement are given in Figure 7 through 10. Building computed friction and vertical reaction forces were obtained as horizontal and vertical reactions for the reference point through which fixed boundary condition was defined for the rigid base. Building displacement, velocity, and acceleration histories were monitored at the bottom of building column on support 6 as shown in Figure 5. The selected location is located where column and beams are connected, and it is far from the loading surfaces to minimize building vibration effects on presented results. The computed friction force histories from the numerical and FE analyses are given in Figure 7. The results show that friction force predicted using the numerical method match with that predicted using FE analysis. However, FE results show that building vibrates on the rigid foundation in the horizontal direction for approximately 1 second. This vibration occurs after the building is found to be in rest per the numerical method. This vibration behavior is not captured by the numerical analysis method. However, it should be noted that this vibration does not affect the maximum sliding distance since it is just a harmonic vibration.

The acceleration histories computed by two analysis methods are given in Figure 8, and they are in very good agreement. However, the FE results show that the structure has some horizontal vibration occurring while the numerical method is not capable of capturing this vibration behavior. This vibration behavior is considered to be due to structure and foundation being rigid, and it is not considered to be realistic.

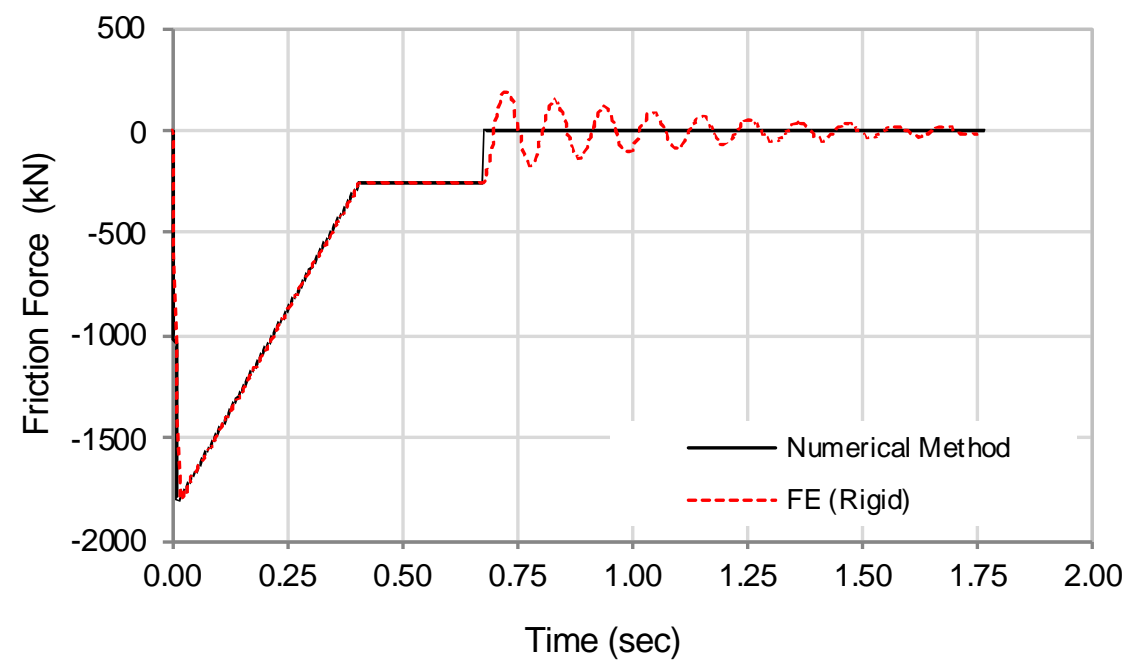

Figure 7. Friction force history 


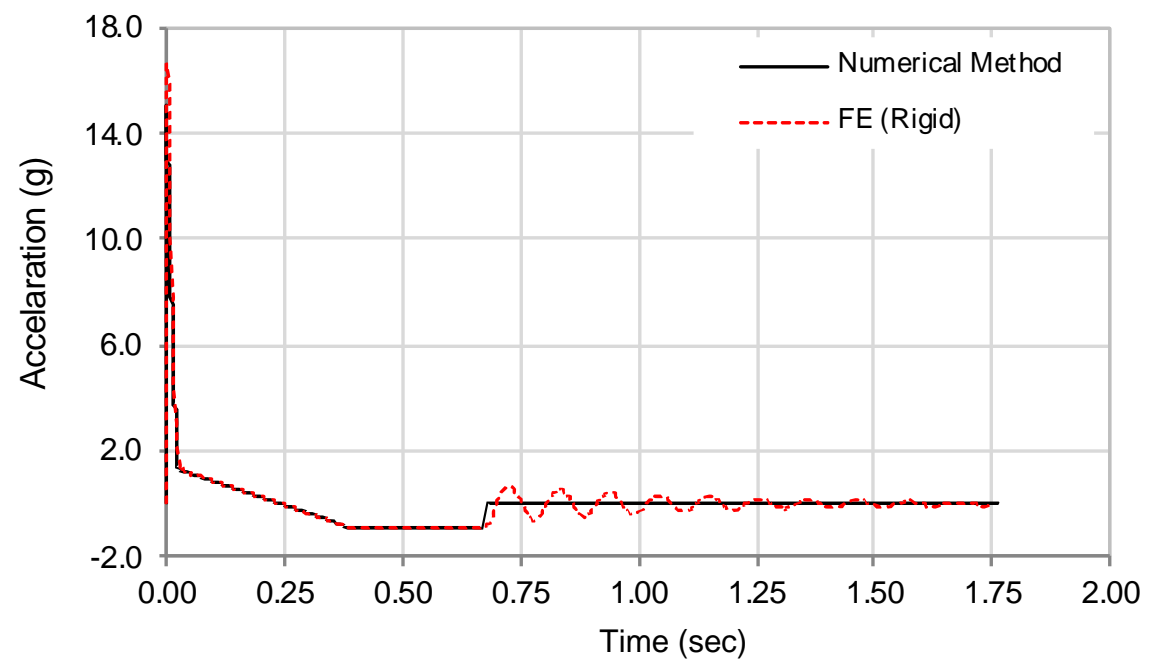

Figure 8. Building horizontal acceleration history

Figure 9 shows horizontal velocity histories for both analysis methods, and both precisely match until vibration starts. The velocity results from FE analysis show vibration of the structure after numerical method shows that the structure is at rest. Figure 10 shows that horizontal displacement histories from both analysis methods perfectly match throughout the analysis. The vibration of the building predicted with FE analysis has a small vibration amplitude and this does not affect the displacement history of the building as expected.

Typically, maximum velocity, acceleration, and displacements (i.e., sliding) values occurring during a blast event are the important performance parameters for blast resistant structures since they indicate the potential of impact/damage and personal injury due to possibility of interaction with the structure and fixed equipment $[2,8,13]$. In conclusion, the results show that the developed numerical analysis method can be used to predict sliding behavior of rigid structures under blast loading. Although it has not been explicitly presented, the foundation reactions predicted using the numerical method are pretty reasonable based on the fact that numerical method reasonably predicts the friction and horizontal forces (i.e., acceleration).

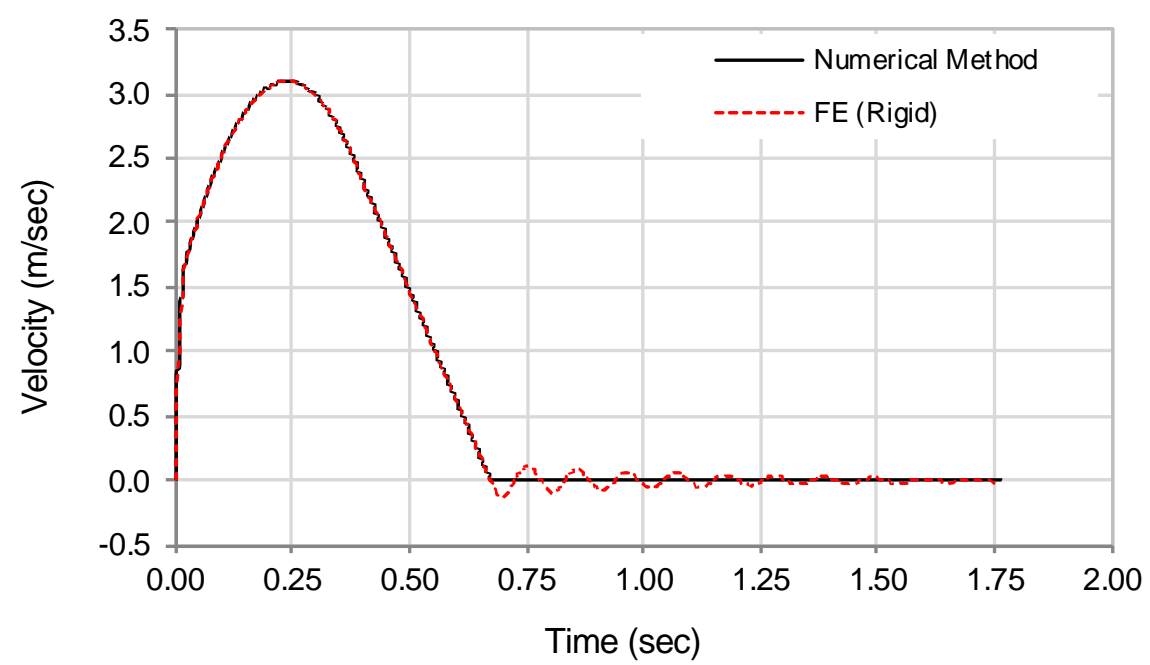

Figure 9. Horizontal velocity history 


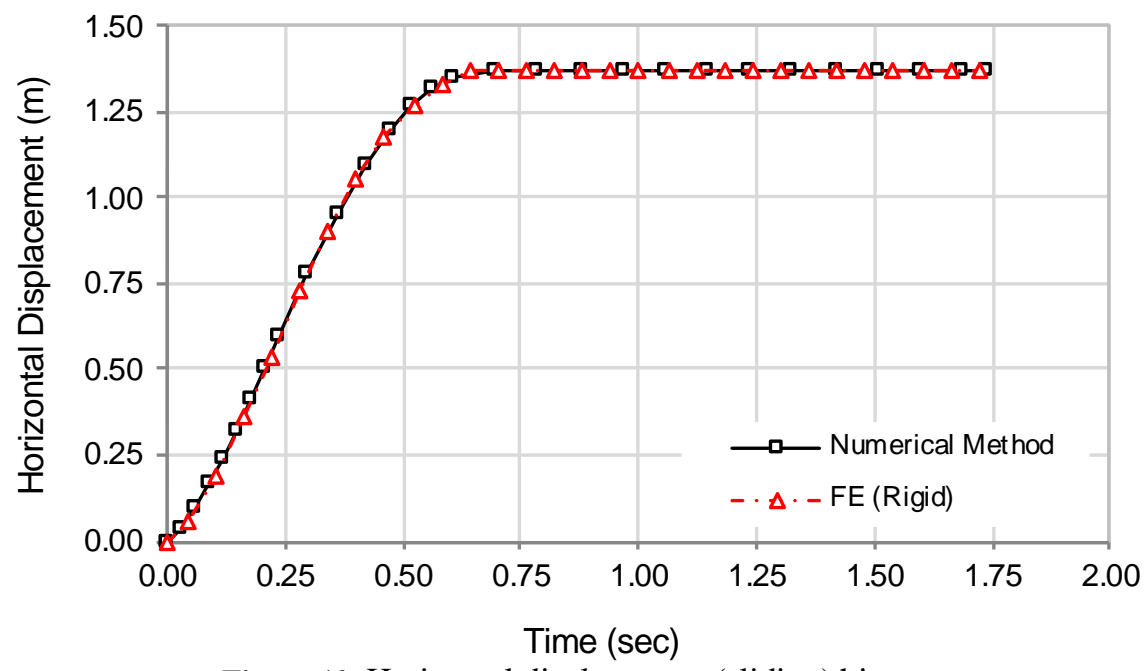

Figure 10. Horizontal displacement (sliding) history

\subsection{Comparison of Numerical and FE Analysis Results for Prototype Building}

Blast analysis of BRMS prototype building with unachored foundation was performed for several friction coefficients using building 3D deformable FE models. The analysis results were used to determine applicability of rigid body approximation (numerical analysis). For all structural members elastic-perfectly plastic steel material properties were used to capture effects of energy dissipation through plastic cyclic deformation of the members. Both dynamic and static coefficient of friction for the interaction between the building and its foundation were assumed to be equal. Three values for coefficient of friction assumed are 0.2, 0.5 and 0.8. Typical value of static friction coefficient between concrete and steel is between 0.40 and 0.50 per various references [2,9], and a little less for the dynamic friction coefficient. Therefore, friction coefficient of 0.5 is considered to be realistic while values of 0.2 and 0.8 were selected to further evaluate applicability of the developed numerical integration method to predict overall structural behavior for large and small sliding displacements due to blast loading.

The FE and numerical blast analysis results of the building for coefficient of friction $0.2,0.5$, and 0.8 are given in Figure 11 through 13 for vertical reaction and horizontal acceleration, velocity, and displacement (i.e., sliding) histories.

The building vertical foundation reaction histories, which is directly related to the friction force history, are very similar for all three friction coefficients. The difference in reaction force time histories is negligible. In addition, the magnitude of maximum reaction force, which controls the foundation design, is approximately $6760 \mathrm{kN}$ for all three cases. However, the maximum foundation reaction computed using the numerical analysis method was only $4860 \mathrm{kN}$ for all three cases of friction coefficient. This difference is mainly because the building is a deformable structure, which vibrates in the vertical direction due to vertical blast loads. This vibration further contributes to foundation vertical reactions, and this is similar to a spring-mass single degree of freedom system under dynamic loads. These results show that vertical reactions predicted using numerical analysis method can be unconservative.

The difference between horizontal acceleration of the building computed using the two analysis methods is substantial. Building horizontal acceleration history computed using the FE analysis for all cases shows a large range of acceleration values with abrupt changes in acceleration history. However, the numerical method shows smooth changes in acceleration during the motion. In other words, the ratio of predicted acceleration values is more than 10 using the two analysis methods. The main reason in this significant difference is the fact that predicting building overall horizontal acceleration using FE analysis is not practical. Theoretically the value of horizontal acceleration changes at every single point of the structure due to building members vibrations while the building is sliding in the horizontal direction. 
Although the reported building accelerations were monitored at the base of the columns, results still shows that the structural members experience much higher accelerations due to their vibration. The computed building horizontal acceleration history using the numerical method should be only considered as building average or gross accelerations.

Despite significant differences in building horizontal acceleration histories predicted using two analysis methods, the rigid-body analysis results for both building horizontal velocity and displacement histories are in good agreement with those computed using FE analyses especially for coefficient of friction values 0.2 and 0.5 . However, as the value of coefficient of friction increases (i.e., 0.8 ), the difference between velocities computed with the two methods increases. Again, this difference is considered to be due to building vibration under dynamic blast loads. On the other hand, it should be noted that a value of 0.8 for coefficient of friction is not realistic. In conclusion, the difference between horizontal velocity histories is negligible for representative values of friction coefficient (i.e., 0.5) between steel and concrete or ground foundation.

The magnitude of horizontal sliding is one of the most important design considerations when a structure is designed to be free-to-slide. The magnitude of flexibility on the utility connections (i.e., power, water, wastewater, and gas) controls limits of building acceptable sliding during a blast event. Therefore, it is crucial that analysis method used should be capable of predicting building sliding with an acceptable accuracy. Building blast analysis results show that sliding distance of the building predicted with numerical analysis is in very good agreement with the FE results despite the differences in building vertical reactions and acceleration histories. In addition, building predicted maximum sliding values with the numerical method are on the conservative side, and difference is approximately $5 \%$ for friction coefficient of 0.3 and 0.5 and less than $1 \%$ for friction coefficient of 0.8 .

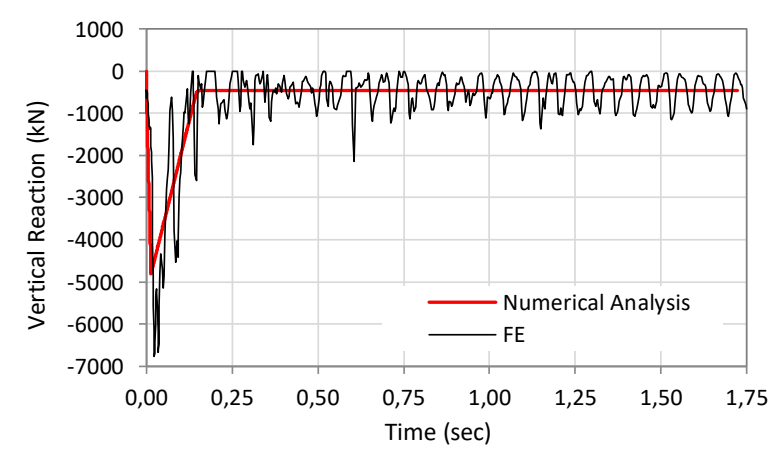

(a)

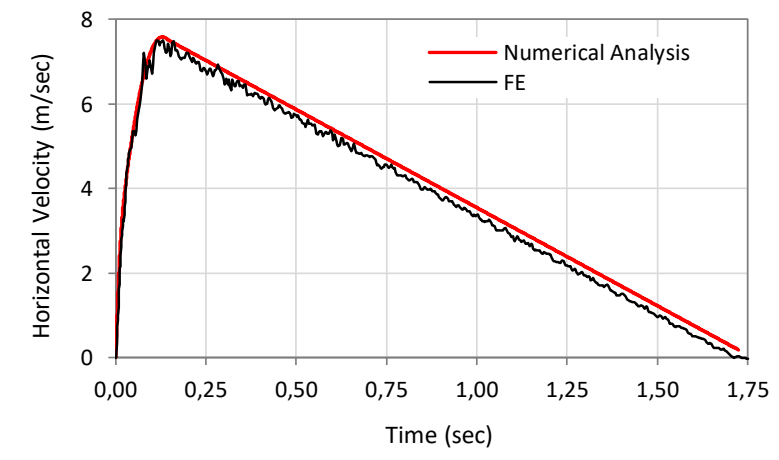

(c)

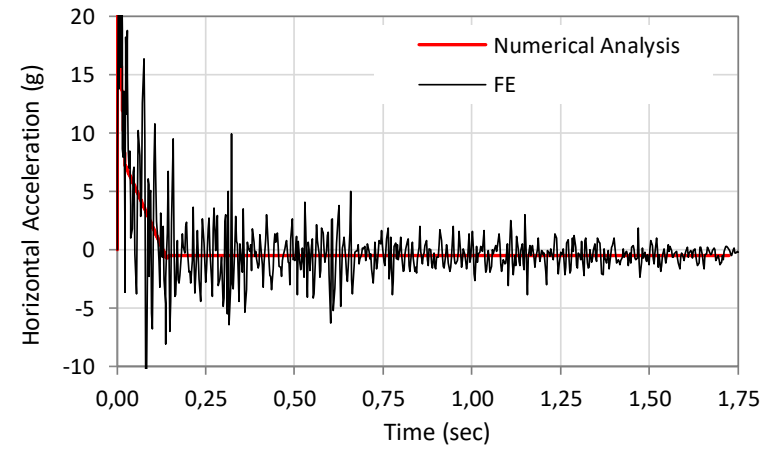

(b)

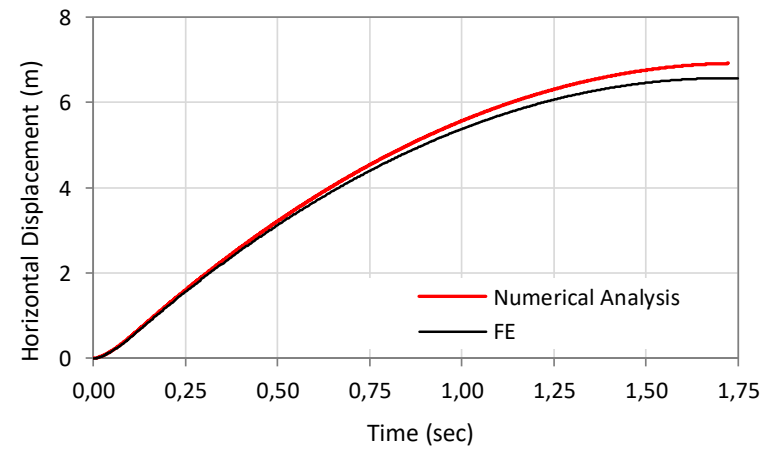

(d)

Figure 11. For $\mu=0.2$ (a) vertical reaction, horizontal (b) acceleration, (c) velocity, and (d) displacement (sliding) 
Erkmen and Balcı / Eskişehir Tech. Univ. J. of Sci. and Technology A-Appl. Sci. and Eng. 20 (4) - 2019

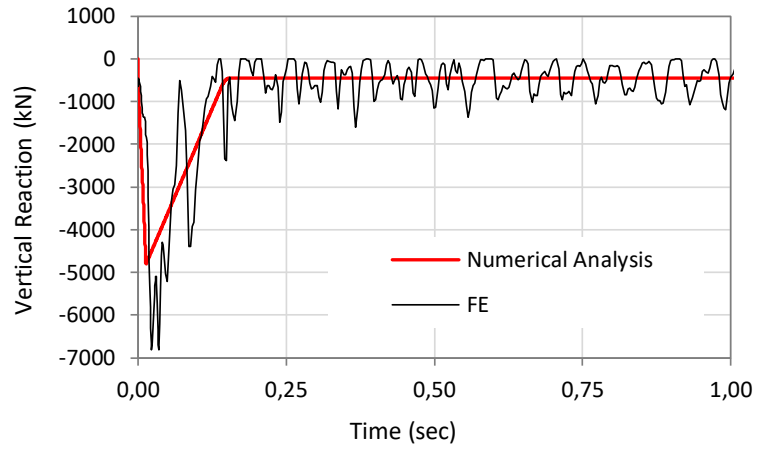

(a)

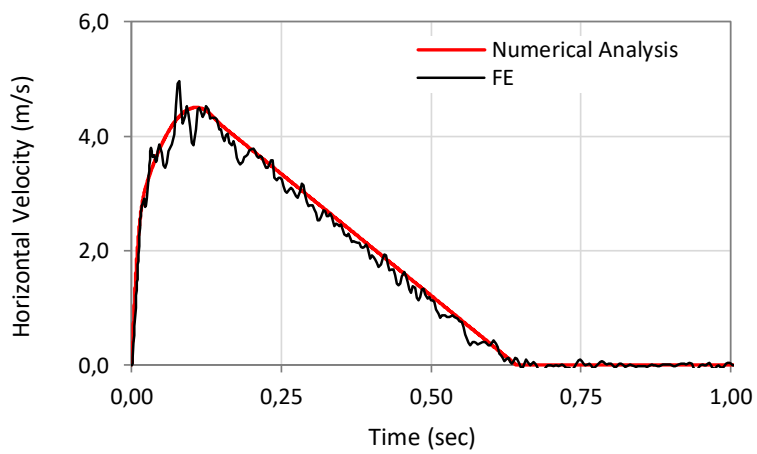

(c)

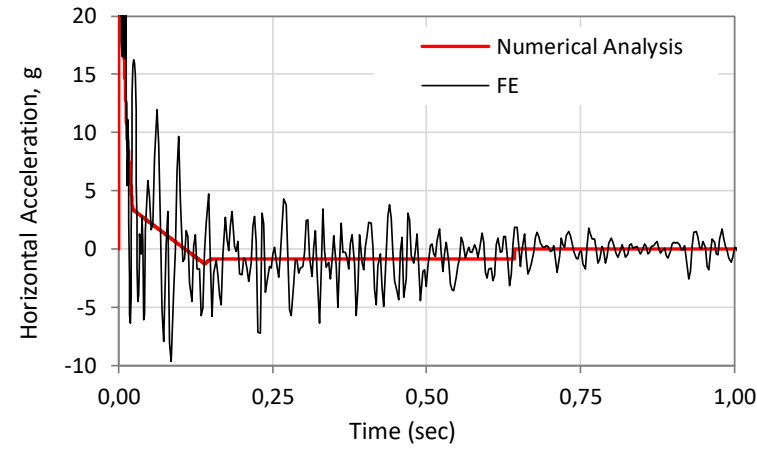

(b)

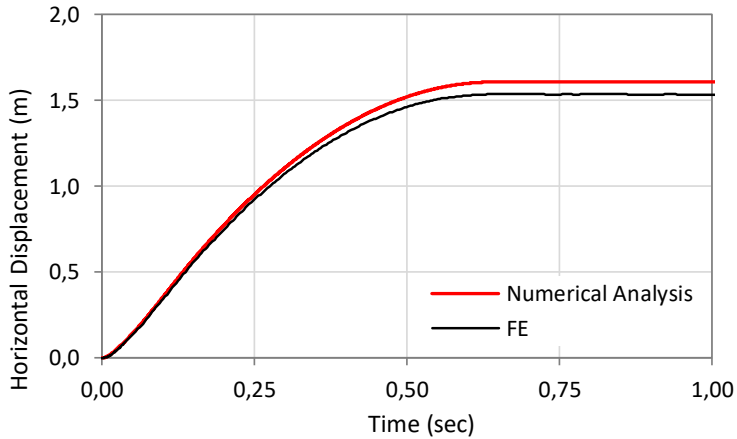

(d)

Figure 12. For $\mu=0.5$ (a) vertical reaction, horizontal (b) acceleration, (c) velocity, and (d) displacement (sliding)

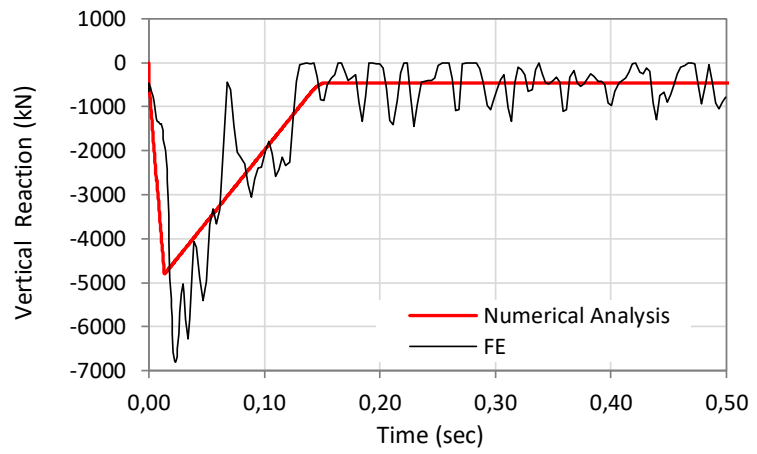

(a)

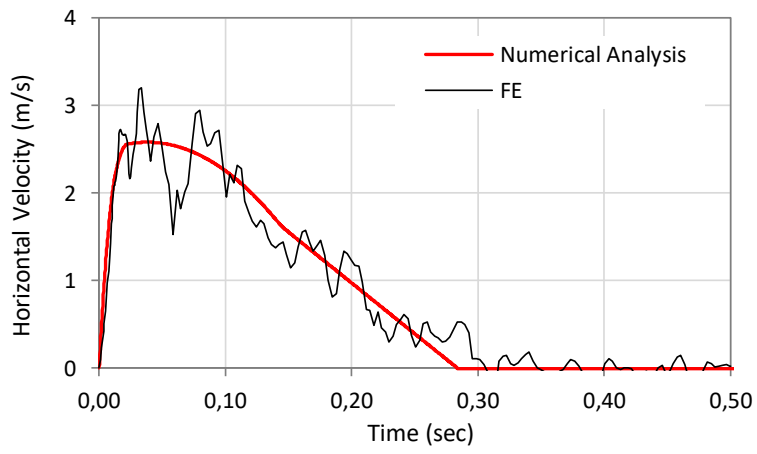

(c)

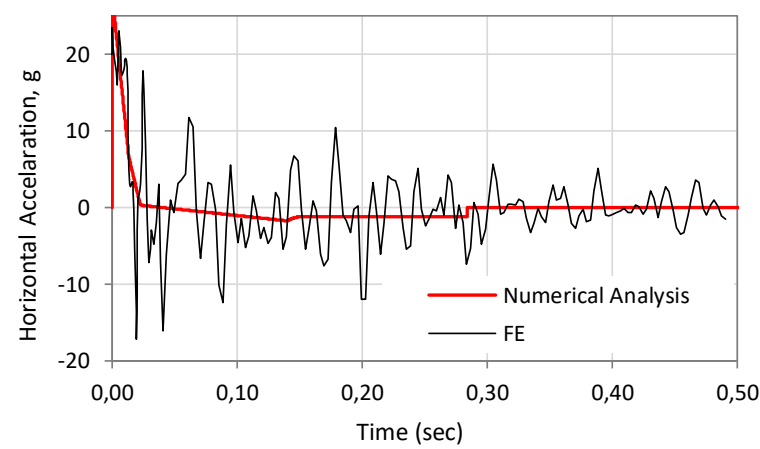

(b)

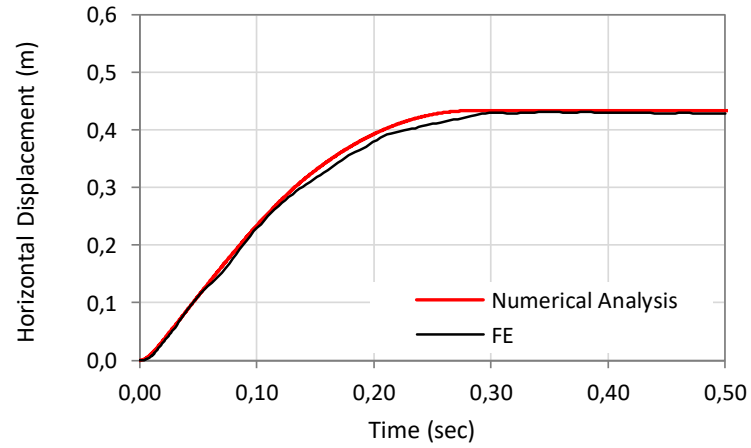

(d)

Figure 13. For $\mu=0.8$ (a) vertical reaction, horizontal (b) acceleration, (c) velocity, and (d) displacement (sliding) 


\section{SUMMARY AND CONCLUSIONS}

Blast analysis of an unanchored prototype modular building subjected to blast loading was investigated. A numerical integration method, which was based on rigid body dynamics was developed and verified. The applicability of developed numerical analysis method to compute building acceleration, velocity, sliding distance, and foundation reactions was evaluated by comparing the results with those obtained from 3D finite element blast analysis of the same structure. The developed finite element model included structural deformation, material yielding, and energy dissipation through cyclic behavior due to material yielding. In addition, dynamic interaction between the building and its foundation including friction and uplift were also included. Based on results presented, the following conclusions are made:

- The results indicate that building vertical reaction predicted using numerical analysis method can be unconservative. The main reason for this is building vibration in the vertical direction.

- The computed building horizontal acceleration history using the numerical method should be only considered as building average accelerations. Horizontal acceleration values at different location of building can be significantly larger than that computed with the numerical method due to structural member vibration under blast or other dynamic loads.

- Building horizontal velocity histories computed using two analysis methods are in reasonable agreement. The difference between the velocity histories is negligible for representative values of friction coefficient (i.e., 0.5), and it is mainly due to building vibration.

- Building predicted maximum sliding values are in very good agreement. The maximum sliding values predicting using the numerical analysis method are on the conservative side, and the difference is approximately $5 \%$ for friction coefficient 0.3 and 0.5 and less than $1 \%$ for friction coefficient of 0.8. Therefore, the numerical analysis method can be used to predict building maximum sliding distance under blast or dynamic loads.

\section{REFERENCES}

[1] Summers P. Design of modular blast-resistant steel-frames buildings in petrochemical facilities. In: ASCE Structures Congress; 24-26 April 2008; Vancouver, Canada.

[2] American Institute of Civil Engineers (ASCE). Design of Blast Resistant Buildings in Petrochemical Facilities. New York, 1997.

[3] Erkmen B. Comparison of blast analysis methods for modular steel structures. İMO Teknik Dergi, 2018; 29: 8253-8277.

[4] U.S. Army Corps of Engineer. Single Degree of Freedom Structural Response Limits for Antiterrorism Design. Protective Design Center, 2008.

[5] Biggs J. M. Introduction to Structural Dynamics. New York: McGraw-Hill Book Company, 1964.

[6] American Institute of Steel Construction (AISC 341-16). Seismic provisions for structural steel buildings. Chicago, Illinois, 2016.

[7] American Institute of Steel Construction (AISC 360-16). Specification for structural steel buildings. Chicago, Illinois, 2016. 
[8] Federal Emergency Management Agency (FEMA 427). Primer for design of commercial buildings to mitigate terrorist attacks. Washington, DC, 2003.

[9] U.S. Department of Defense. Structures to resist the effects of accidental explosions. Technical Manual UFC 3-340-02, Washington, DC, 2007.

[10] Balc1 B. Blast performance of BRMS structures with sliding foundation and effects of dynamic interaction of structural members on ESDOF blast analysis. MSc, Özyeğin University, Istanbul, Turkey, 2018.

[11] Stea W, Weissman S, Dobbs N, Amman \& Whitney Consulting Engineers. Overturning and Sliding Analysis of Reinforced Concrete Protective Structures. Technical Publication TR4921, US Army Picatinny Arsenal, Dover NJ, 1976.

[12] Simula. Abaqus/CAE User’s Guide. 2014.

[13] Federal Emergency Management Agency (FEMA 426). Reference manual to mitigate potential terrorist attacks against buildings. Washington, DC, 2003. 